\title{
Development of High-Temperature Solders: Contribution of Transmission Electron Microscopy
}

\author{
Jee-Hwan Bae, Keesam Shin ${ }^{1}$, Joon-Hwan Lee ${ }^{2}$, Mi-Yang Kim², Cheol-Woong Yang* \\ School of Advanced Materials Science \& Engineering, Sungkyunkwan University, Suwon 440-746, Korea \\ ${ }^{1}$ School of Nano and Advanced Materials Engineering, Changwon National University, Changwon 641-773, Korea \\ ${ }^{2}$ Advanced Materials \& Device Lab, Corporate R\&D Institute, Samsung Electro-Mechanics Co., Suwon 443-743, Korea
}

*Correspondence to:

Yang CW,

Tel: +82-31-290-7362

Fax: +82-31-290-7371

E-mail: cwyang@skku.edu

Received June 22, 2015

Revised June 26, 2015

Accepted June 26, 2015
This article briefly reviews the results of recently reported research on high-temperature $\mathrm{Pb}$-free solder alloys and the research trend for characterization of the interfacial reaction layer. To improve the product reliability of high-temperature $\mathrm{Pb}$-free solder alloys, thorough research is necessary not only to enhance the alloy properties but also to characterize and understand the interfacial reaction occurring during and after the bonding process. Transmission electron microscopy analysis is expected to play an important role in the development of high-temperature solders by providing accurate and reliable data with a high spatial resolution and facilitating understanding of the interfacial reaction at the solder joint.

Key Words: Step soldering, Melting temperature, Spatial resolution, Scanning electron microscopy, Transmission electron microscopy

\section{INTRODUCTION}

As the human health hazard and environmental problems due to hazardous substances used in electronic packaging became an issue, the European Union enacted the Restriction of Hazardous Substances (RoHS) Directive regarding electrical and electronic products in 2006. Thereafter, a number of countries introduced environmental regulations regarding imported electronic products.

The study of medium-temperature $\mathrm{Pb}$-free solder, represented by $\mathrm{Sn}$-Ag-based solder, to replace $\mathrm{Sn}-37 \mathrm{wt} \% \mathrm{~Pb}$ (hereinafter the notation $\mathrm{Sn}-37 \mathrm{~Pb}$ is used, omitting the unit of $\mathrm{wt} \%$ ) for packaging technology is essentially complete. $\mathrm{Sn}-\mathrm{Ag}-\mathrm{Cu}$ solder is a representative alloy and is widely used as a standard solder alloy (Suganuma, 2004). However, little research has examined the high-temperature $\mathrm{Pb}$-free solder used for step soldering, power devices, and flip-chip connections because an exemption for high-melting-temperature-type solders (i.e., lead-based alloys containing $85 \mathrm{wt} \%$ or more lead) has been added to the RoHS Directive, and this exemption is permitted owing to the lack of viable $\mathrm{Pb}$-free alternative alloys with similar melting points. Thus, $\mathrm{Pb}$-containing high-temperature solders are still heavily used by many manufacturers. Nevertheless, the development of high-temperature, highreliability, and eco-friendly $\mathrm{Pb}$-free solder is essential because of not only environmental issues but also processing issues. In particular, in step soldering, the solder used for the first step must have a higher melting temperature than that used for the next step. In addition, $\mathrm{Sn}-37 \mathrm{~Pb}$ (melting point $T_{m}=183^{\circ} \mathrm{C}$ ) has been replaced by $\mathrm{Sn}$-Ag-Cu solder $\left(T_{m}=221^{\circ} \mathrm{C}\right)$, and the reflow temperature was accordingly increased by $\sim 40^{\circ} \mathrm{C}$, which implies that solders having melting temperatures higher than $\sim 250^{\circ} \mathrm{C}$ are required for step soldering if $\mathrm{Sn}-\mathrm{Ag}$-Cu solder is used in the secondary mounting process.

Vianco defined "ultrahigh-temperature" solder as "solder used in environments having sustained temperatures as high

This work was supported by NRF grants funded by the Korean government (MSIP and MTIE) (No. 2011-0019984, No. 2011-0030058, and No. 10041134) and in part by grants funded by Samsung Electro-Mechanics Co. through the Interface Research Center at Sungkyunkwan University. The authors are also grateful for the technical support provided by the Cooperative Center for Research Facilities (CCRF) at Sungkyunkwan University.

@ This is an open-access article distributed under the terms of the Creative Commons Attribution Non-Commercial License (http://creativecommons.org/licenses/by-nc/4.0) which permits unrestricted noncommercial use, distribution, and reproduction in any medium, provided the original work is properly cited.

Copyrights @ 2015 by Korean Society of Microscopy 
as $300^{\circ} \mathrm{C}$ and momentary temperature excursions to levels as high as $350^{\circ} \mathrm{C}$ " (Vianco, 2002). High-temperature solders are generally required to have adequate physical properties, including high ductility and thermal conductivity and low electrical resistance, and to be cheap and eco-friendly. In particular, they must have a higher solidus temperature than the secondary reflow temperature $\left(\sim 250^{\circ} \mathrm{C}\right)$ of the intermediate $T_{m}$ solder packaging and have a lower liquidus temperature than the glass transition temperature $\left(\sim 400^{\circ} \mathrm{C}\right)$ of polymer-based substrate materials.

Alloys containing Au-, Bi-, Cd-, Sn-, and Zn-based solders reportedly satisfy these conditions. This article considers $\mathrm{Bi}-, \mathrm{Sn}-$, and $\mathrm{Zn}$-based high-temperature $\mathrm{Pb}$-free solder candidates, excluding Au-based alloys, which are costly, and Cd-based alloys, which are harmful to the environment.

\section{CANDIDATES FOR HIGH-TEMPERATURE PB- FREE SOLDERS}

$\mathrm{Sn}$-Sb solder has melting points of $235^{\circ} \mathrm{C}$ and $240^{\circ} \mathrm{C}$ for the representative compositions of Sn-5Sb and Sn-10Sb, respectively, and the melting point rises as the $\mathrm{Sb}$ content increases by peritectic reaction (Fig. 1A) (Okamoto, 2012). It has not only excellent wettability and high mechanical properties at room temperature, but also an electrical resistance similar to that of $\mathrm{Pb}-\mathrm{Sn}$ solder (Geranmayeh \& Mahmudi, 2005; El-Daly et al., 2011a, 2011b). However, it has drawbacks such as toxicity due to the presence of $\mathrm{Sb}$ and a too-low liquidus line for it to be used for step soldering. $\mathrm{Bi}$ - $\mathrm{Ag}$ solder has a melting temperature of $262.5^{\circ} \mathrm{C}$ at the eutectic composition (Bi-2.5Ag) (Fig. 1B) (Karakaya \&

B

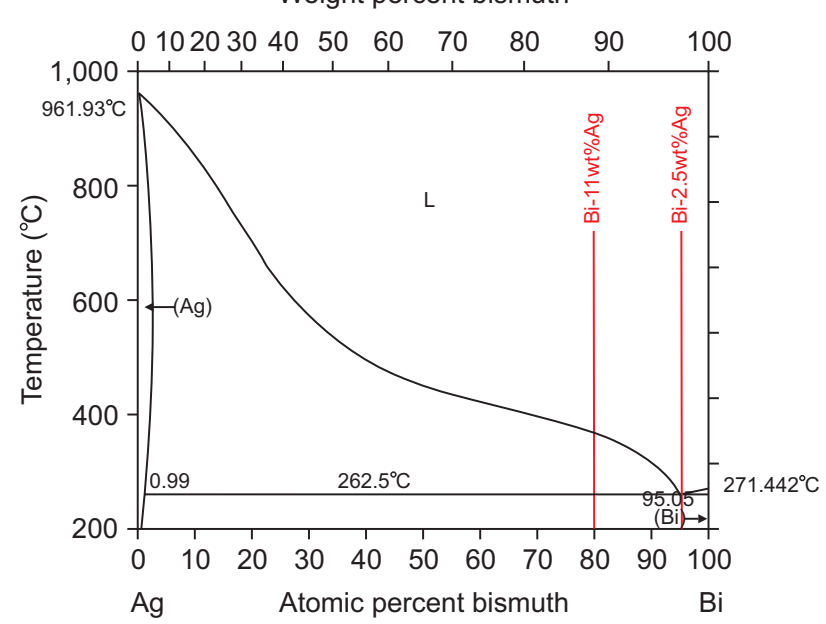

Fig. 1. Binary phase diagrams of $\mathrm{Sn}-\mathrm{Sb}(\mathrm{A})$ and $\mathrm{Bi}-\mathrm{Ag}(\mathrm{B})$. Red lines denote typical solder compositions.

A

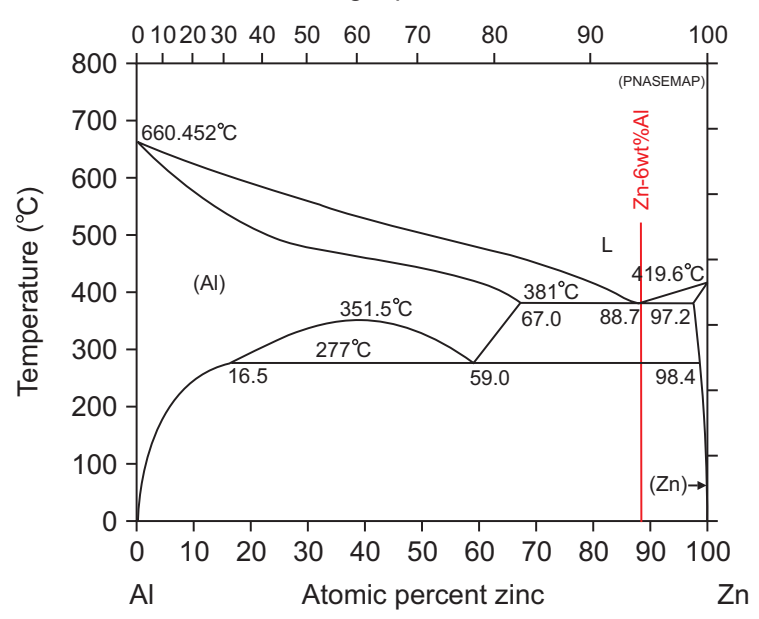

B

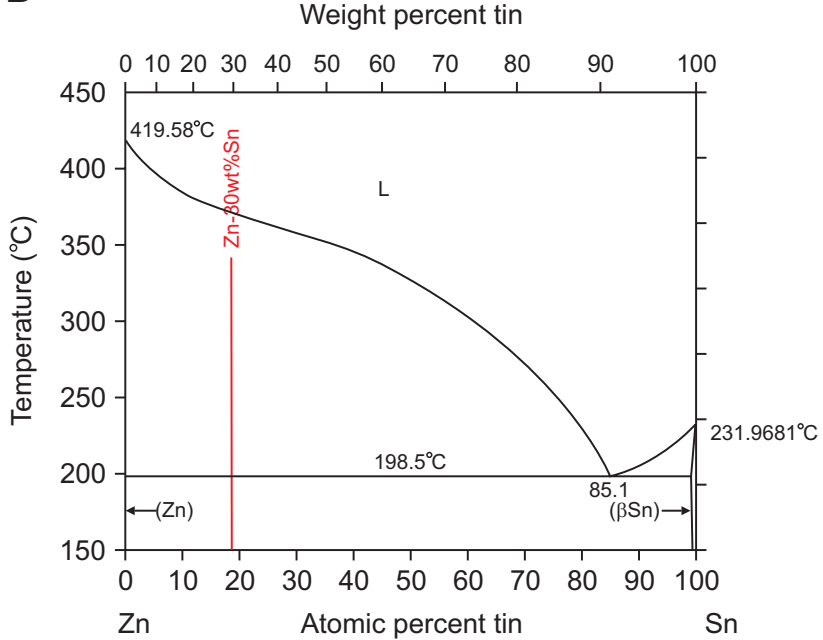

Fig. 2. Binary phase diagrams of $\mathrm{Zn}-\mathrm{Al}$ (A) and $\mathrm{Zn}-\mathrm{Sn}$ (B). Red lines denote typical solder compositions. 
Table 1. Advantages and disadvantages of high-temperature $\mathrm{Pb}$-free solder candidates

\begin{tabular}{cll}
\hline Type & \multicolumn{1}{c}{ Advantage } & \multicolumn{1}{c}{ Disadvantage } \\
\hline $\mathrm{Sn}-\mathrm{Sb}$ & Good wettability, good creep properties & Low liquidus line, toxic \\
$\mathrm{Bi}-\mathrm{Ag}$ & Adequate melting range & Low conductivity, bad electrical resistance \\
$\mathrm{Zn}-\mathrm{Sn}$ & Good ductility, high tensile strength, low cost & Highly corrosive, liquid phase $\left(199^{\circ} \mathrm{c}\right)$ at process temperature \\
$\mathrm{Zn}-\mathrm{Al}$ & Easy to use in field applications, low cost & Highly corrosive, poor wettability \\
\hline
\end{tabular}

Thompson, 1993). Research on this solder alloy system is still incomplete, owing mainly to its inferior thermal and electrical conductivity as well as poor workability. A recent study reported that the electrical resistivity of the $\mathrm{Bi}-11 \mathrm{Ag}$ alloy is $86.5 \mu \Omega / \mathrm{cm}$, which is much lower than that of the Bi$2.5 \mathrm{Ag}$ eutectic alloy, $116.5 \mu \Omega / \mathrm{cm}$ (Song et al., 2007a). Song et al. (2007b) have examined rare-earth-material-doped Bi-Ag solders with various $\mathrm{Ag}$ concentrations. They suggested that the addition of small amounts of rare earth elements may enhance the wettability of $\mathrm{Bi}-\mathrm{Ag}$ solder on $\mathrm{Cu}$ substrates and the shear strength of the solder joints (Song et al., 2007b). $\mathrm{Zn}$-based solders can be divided into $\mathrm{Zn}$ - $\mathrm{Al}$ and $\mathrm{Zn}$-Sn types. $\mathrm{A} \mathrm{Zn}-\mathrm{Al}$ alloy with a eutectic melting point of $381^{\circ} \mathrm{C}(\mathrm{Zn}-6 \mathrm{Al})$, as shown in Fig. 2A (Murray, 1983), has been studied because the melting range of $\mathrm{Zn}-\mathrm{Al}$ solder is similar to that of $\mathrm{Pb}-5 \mathrm{Sn}$ solder (so it can be used immediately in industry) (Kim et al., 2008; Kang et al., 2009). The price of zinc and aluminum is very low (they are even cheaper than lead). However, $\mathrm{Zn}$-Al solder has several drawbacks compared to other solder alloys. It has a galvanic corrosion problem due to the corrosive metal zinc and poor wettability due to the high oxygen affinity of $\mathrm{Zn}$ and $\mathrm{Al}$ materials. A few papers reported improvement of its properties by the addition of a third material (e.g., $\mathrm{Ag}, \mathrm{Cu}$, $\mathrm{Ge}, \mathrm{Mg}$ ) to $\mathrm{Zn}-\mathrm{Al}$ solder (Shimizu et al., 1999; Aksoz et al., 2011; Cheng et al., 2012; Gancarz et al., 2012).

In the case of $\mathrm{Zn}$-Sn solder alloy, a hypereutectic composition, $\mathrm{Zn}-(20,30,40) \mathrm{Sn}$, where the eutectic composition is $\mathrm{Sn}-8.8 \mathrm{Zn}$ (Fig. 2B) (Moser et al., 1985), has been studied. This alloy system has the advantages of excellent thermal conductivity and mechanical properties (ductility and high ultimate tensile strength) and oxidation resistance in high-temperature highhumidity conditions (Lee et al., 2005; Santos et al., 2014). However, in addition to the corrosion problem due to zinc, there is a serious problem that the solidified solder joint returns to a solid+liquid mixed phase at the secondary reflow temperature $\left(\sim 250^{\circ} \mathrm{C}\right)$, which is higher than the eutectic temperature of $199^{\circ} \mathrm{C}$ (Fig. 2B). Nevertheless, Suganuma et al. (2009) suggested that this hypereutectic alloy can be used as a high-temperature solder by controlling the liquid fraction at the secondary reflow temperature. They reported that the volume expansion caused by formation of the liquid phase (remelting) in the solder joint is not large enough to distort the bonding structure if the $\mathrm{Sn}$ content is $<30 \mathrm{wt} \%$ (Lee et al.,
2005).

Table 1 summarizes the advantages and disadvantages of high-temperature $\mathrm{Pb}$-free solder candidates.

\section{INTERFACIAL REACTION BETWEEN HIGH- TEMPERATURE PB-FREE SOLDER AND SUBSTRATES}

When solder is joined to a substrate, an interface intermetallic compound (IMC) is formed by diffusion of the constituent atoms in the solder and substrate. These IMCs grow by solidliquid phase diffusion and solid-solid phase diffusion. Solidliquid diffusion occurs by mass transport between the melted solder (liquid) and substrate (solid) during the bonding process, whereas solid-solid diffusion is responsible for IMC growth after the bonding process. IMC growth reportedly has an important effect on the reliability of solder joints.

According to research papers on $\mathrm{Zn}$-based solder, $\mathrm{Cu}-\mathrm{Zn}$ IMCs $\left(\mathrm{CuZn}_{4}\right.$ and $\left.\mathrm{Cu}_{5} \mathrm{Zn}_{8}\right)$ were formed when $\mathrm{Zn}$-based solders were bonded to a $\mathrm{Cu}$ substrate (Takaku et al., 2008; Hui et al., 2009; Kim et al., 2009a, 2009b; Haque et al., 2010a, 2010b; Mahmudi \& Eslami, 2010; Takahashi et al., 2010; Haque et al., 2012; Wang et al., 2012). Takaku et al. (2009) reported that an $\mathrm{Al}_{3} \mathrm{Ni}_{2}$ IMC was formed when $\mathrm{Zn}-\mathrm{Al}-\mathrm{Cu}$ solder was joined to a $\mathrm{Ni}$ substrate. The linear relationship between $\mathrm{d}$ (the IMC thickness) and the square root of $t$ (the time) was confirmed and follows the parabolic law

$$
d=k \sqrt{t}
$$

where $k$ represents the growth rate coefficient for the consumption rate (experimental values).

Bi-Ag solder alloy does not form any interfacial reaction layer with a $\mathrm{Cu}$ substrate and makes solder joints in such a way that the Ag penetrates the grain boundaries of the $\mathrm{Cu}$ substrate. Further, $\mathrm{NiBi}_{3}$ and $\mathrm{NiBi}$ phases were reportedly formed during connection with a Ni substrate (formation of the interface reaction layer differs depending on the Ag composition of Bi-Ag solders) (Song et al., 2006; Shi et al., 2010; Iseki \& Takamori, 2012). In the case of Sn-based solder alloys, $\mathrm{Cu}_{3} \mathrm{Sn}$ and $\mathrm{Ni}_{3} \mathrm{Sn}_{4}$ IMCs were reportedly formed when the solder joined with $\mathrm{Cu}$ and Ni substrates (Chen et al., 2006, 2008).

As summarized in Table 2, the number of papers that have studied the interface reaction layer is still small, and the research results consist only of simple phase analysis using 
scanning electron microscopy (SEM) images and phase diagram data.

\section{NEED FOR TRANSMISSION ELECTRON MICROSCOPY ANALYSIS}

In previously published papers, the interface reaction layer between the solder and the substrate has generally been investigated by a combination of microstructural analysis using SEM, chemical composition analysis using energy dispersive $\mathrm{X}$-ray spectroscopy (EDS), and phase analysis using X-ray diffraction (XRD) in conjunction with phase diagrams (Chen et al., 2006; Song et al., 2006; Chen et al., 2008; Takaku et al., 2008; Hui

Table 2. Numbers of papers per analytical method

\begin{tabular}{lccc}
\hline Type & $\begin{array}{c}\text { No. of papers } \\
\text { published since 2000 }\end{array}$ & $\begin{array}{c}\text { No. of papers } \\
\text { reporting IMC } \\
\text { analysis using SEM }\end{array}$ & $\begin{array}{c}\text { No. of papers } \\
\text { reporting IMC } \\
\text { analysis using TEM }\end{array}$ \\
\hline Sn-Sb & 5 & 2 & 0 \\
$\mathrm{Bi}-\mathrm{Ag}$ & 5 & 4 & 0 \\
$\mathrm{Zn}-\mathrm{Al}$ & 12 & 6 & 1 \\
$\mathrm{Zn}-\mathrm{Sn}$ & 8 & 4 & 0 \\
\hline
\end{tabular}

IMC, intermetallic compound; SEM, scanning electron microscopy; TEM, transmission electron microscopy. et al., 2009; Kim et al., 2009a, 2009b; Haque et al., 2010a, 2010b; Mahmudi \& Eslami, 2010; Shi et al., 2010; Takahashi et al., 2010; Haque et al., 2012; Iseki \& Takamori, 2012; Wang et al., 2012). However, SEM and EDS analysis cannot yield accurate results because of technical limitations such as low spatial resolution (large electron beam-specimen interaction volume) and ambiguous peaks and noise signals. XRD analysis is also not a suitable method for analyzing the phase of the interfacial reaction layer because of the difficulty of selecting the analysis region and fine grain detection limit settings.

Therefore, transmission electron microscopy (TEM) analysis has become important for accurate characterization of interfacial reaction layers. By employing various TEM imaging, diffraction, and spectroscopic techniques, it is possible to obtain reliable analysis results with high spatial resolution. One can obtain crystallographic information using versatile electron diffraction techniques, including selected area electron diffraction, nanobeam electron diffraction, and convergent beam electron diffraction techniques, and chemical composition data from EDS and electron energy loss spectroscopy analysis of a specimen several tens of nanometers thick.

We have studied the interfacial reaction layers between Sn3.5Ag intermediate-temperature $\mathrm{Pb}$-free solder and electroless nickel immersion gold plating $(\mathrm{Ni}-15 \mathrm{at} \% \mathrm{P})$ on a Cu substrate
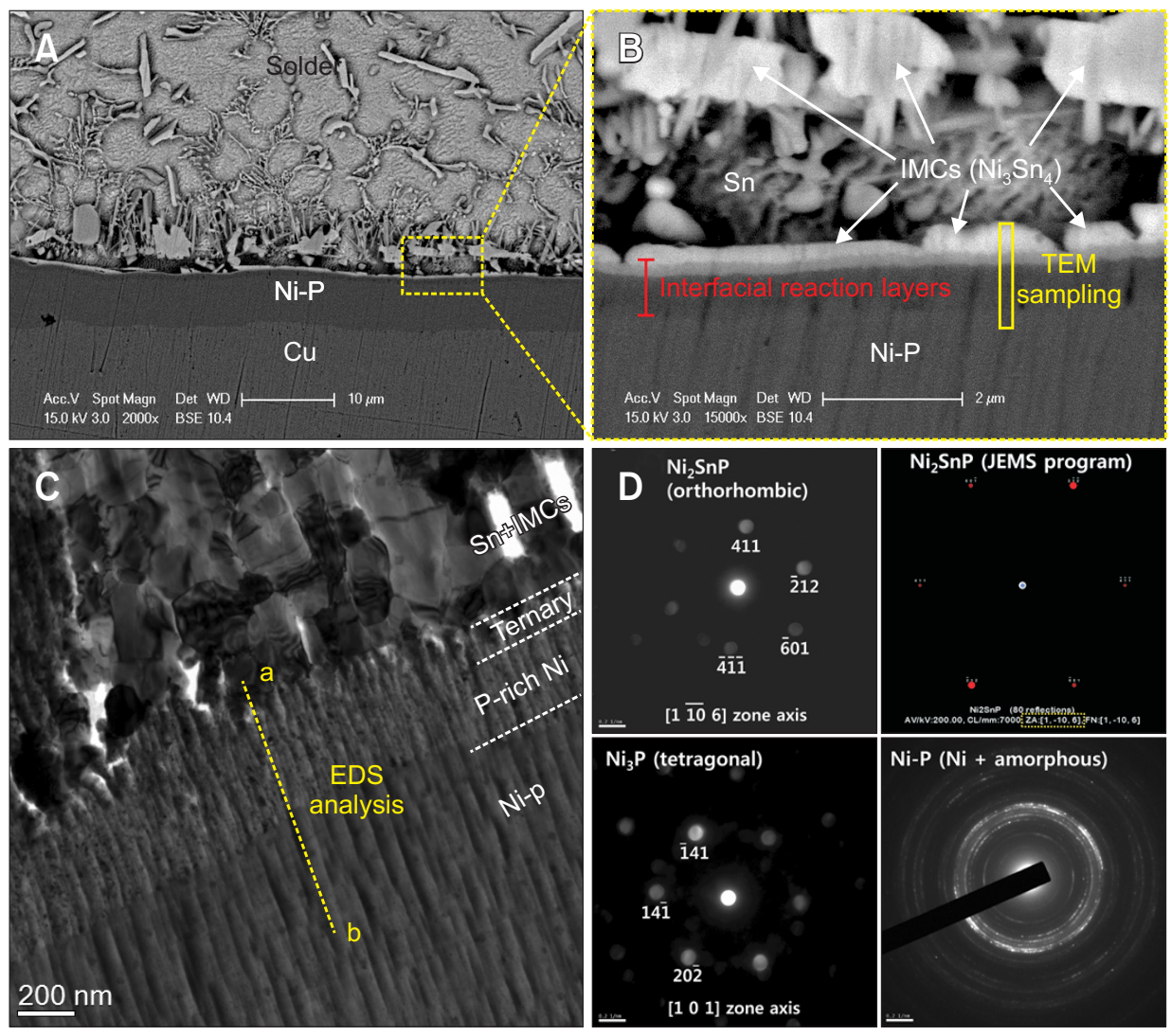

Fig. 3. Electron microscopy images of interfacial reaction layer between $\mathrm{Sn}$ $3.5 \mathrm{Ag}$ solder and $\mathrm{Cu}$ electroless nickel immersion gold plating on $\mathrm{Cu}$ substrate. (A, B) Scanning electron microscopy images with low and high magnification. $(C, D)$ TEM image and diffraction pattern of each layer. IMC, intermetallic compound; TEM, transmission electron microscopy; EDS, energy dispersive X-ray spectroscopy. 


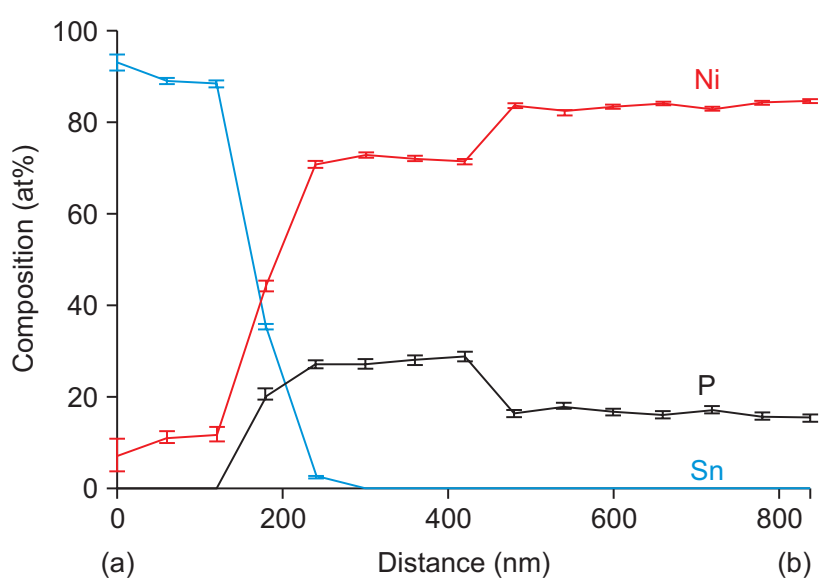

Fig. 4. Scanning transmission electron microscopy (STEM)-energy dispersive X-ray spectroscopy (EDS) analysis showing compositional variation of three elements ( $\mathrm{Ni}, \mathrm{P}, \mathrm{Sn}$ ) at the intermetallic compound/ Ni-P plating layer interface. STEM-EDS was conducted along the yellow dotted line (from ' $a$ ' to ' $b$ ') in Fig. 3C.

using both SEM and TEM. Fig. 3A and B are SEM images of the reaction area after reflowing at $280^{\circ} \mathrm{C}$. Only needle-shaped IMCs were observed at the interface at low magnification. Two thin layers having a different contrast were observed at the joining area in the high-magnification image; however, accurate phase analysis was impossible because of the abovementioned problems. Fig. 3C and D are analysis results obtained from a TEM sample prepared by ultramicrotomy at the indicated area in Fig. 3B. Although Fig. 3C could not provide a perfect sample image because of knife marks created by mechanical stress during sectioning, each layer of the joining interface can be clearly observed (Fig. 3C), and intermediate layers were confirmed to have deposits of different phases $\left(\mathrm{Ni}_{2} \mathrm{SnP}, \mathrm{Ni}_{12} \mathrm{P}_{5}\right.$, and $\left.\mathrm{Ni}-\mathrm{P}\right)$ using diffraction pattern analysis (Fig. 3D). The Ni2SnP ternary phase was verified by running the JEMS software (Stadelmann, 1987), a simulation program for diffraction patterns and high- resolution images, along the identical zone axis. In the Ni-P plating layer, two ring patterns (broad amorphous ring pattern and sharp Ni polycrystalline ring pattern) were observed simultaneously. The results of phase identification can be crosschecked and confirmed by performing scanning TEM (STEM)EDS analysis (Fig. 4). Because the spatial resolution of STEMEDS is superior to that of SEM-EDS analysis, it was possible to obtain a more accurate composition value that matched well the stoichiometry of each phase.

\section{CONCLUSIONS}

In this paper, we reviewed the results of recently reported research on high-temperature $\mathrm{Pb}$-free solder alloys and research trends for characterization of the interfacial reaction layer. Research on these alloys should be conducted continuously to mitigate the drawbacks and improve the properties of these high-temperature solder alloys for eventual use in the field. The number of research papers on the interfacial reaction layer is also increasing gradually. A thin interface reaction layer is generally known to be good for enhancing the bonding property of solder joints because IMCs are brittle and exhibit poor electrical characteristics.

To improve the product reliability of high-temperature $\mathrm{Pb}$ free solder alloys, thorough research is necessary not only to enhance the alloy properties but also to characterize the interfacial reaction layer formed during and after the bonding process. Accordingly, the contribution of TEM analysis to the development of high-temperature $\mathrm{Pb}$-free solders is expected to become more important, and it will provide insight into interfacial reactions at the solder joint.

\section{CONFLICT OF INTEREST}

No potential conflict of interest relevant to this article was reported.

\section{REFERENCES}

Aksoz S, Ocak Y, Marasli N, and Keslioglu K (2011) Determination of thermal conductivity and interfacial energy of solid $\mathrm{Zn}$ solition in the Zn-Al-Bi eutectic system. Exp. Therm. Fluid. Sci. 35, 395-404.

Chen S W, Chem P Y, and Wang C H (2006) Lowering of Sn-Sb alloy melting points caused by substrate dissolution. J. Electron. Mater. 35, 1982-1985.

Chen S W, Zi A, Chen P, Wu H, Chen Y, and Wang C (2008) Interfacial reactions in the $\mathrm{Sn}-\mathrm{Sb} / \mathrm{Ag}$ and $\mathrm{Sn}-\mathrm{Sb} / \mathrm{Cu}$ couples. Mater. Chem. Phys. 111, 1719.

Cheng F, Gao F, Wang Y, Wu Y, Ma Z, and Yang J (2012) Sn addition on the tensile properties of high temperature $\mathrm{Zn}-4 \mathrm{Al}-3 \mathrm{Mg}$ solder alloys. Microelectron. Reliab. 52, 579-584.
El-Daly A A, Fawzy A, Mohamad A Z, and El-Taher A M (2011a) Microstructural evolution and tensile properties of Sn-5Sb solder alloy containing small amount of Ag and Cu. J. Alloy. Compd. 509, 4574-4582.

El-Daly A A, Mohamad A Z, Fawzy A, and El-Taher A M (2011b) Creep behavior of near-peritectic Sn-5Sb solders containing small amounts of Ag and Cu. Mater. Sci. Eng. A 528, 1055-1062.

Gancarz T, Pstrus J, Fima P, and Mosinska S (2012) Thermal properties and wetting behavior of high temperature $\mathrm{Zn}$-Al-In solders. J. Mater. Eng. Perform. 21, 599-605.

Geranmayeh A R and Mahmudi R (2005) Power law identation creep of Sn-5\%Sb solder alloy. J. Mater. Sci. 40, 3361-3366. 
Haque A, Lim B H, Haseeb A S M A, and Masjuki H H (2012) Die attach properties of $\mathrm{Zn}$-Al-Mg-Ga based high-temperature lead-free solder on Cu lead-frame. J. Mater. Sci.: Mater. Electron. 23, 115-123.

Haque A, Won YS, Haseeb A S M A, and Masjuki H H (2010a) Investigations on $\mathrm{Zn-Al-Ge} \mathrm{alloys} \mathrm{as} \mathrm{high} \mathrm{temperature} \mathrm{die} \mathrm{attach} \mathrm{material.} \mathrm{Electronic}$ System-Integration Technology Conference (ESTC) 3, 1-5.

Haque A, Won Y S, Lim B H, Haseeb A S M A, and Masjuki H H (2010b) Effect of Ni metallization on interfacial reactions and die attach properties of Zn-Al-Mg-Ga high temperature lead-free solder. International Electronic Manufacturing Technology Conference 34, 1-6.

Hui W, Siyuan H, Xuming C, and Deping H (2009) Interfacial structure and mechanical properties of aluminium foam joints fluxless-soldered with Zn-Al-Cu base alloy. Acta Metall. Sin. 45, 723-728.

Iseki T and Takamori M (2012) Development of Bi-based Pb-free solders for high-temperature. J. Jpn. Inst. Electron. Pack. 15, 153-157.

Kang N H, Na H S, Kim S J, and Kang C Y (2009) Alloy design of Zn-Al-Cu solder for ultra high temperatures. J. Alloy. Compd. 467, 246-250.

Karakaya I and Thompson W T (1993) The Ag-Bi (silver-bismuth) system. J. Phase Equilib. 14, 525-530.

Kim S J, Kim K S, Kim S S, Kang C Y, and Suganuma K (2008) Characteristics of $\mathrm{Zn}$-Al-Cu alloys for high temperature solder application. Mater. Trans. 49, 1531-1536.

Kim S, Kim K S, Kim S S, and Suganuma K (2009b) Interfacial reaction and die attach properties of Zn-Sn high-temperature solders. J. Electron. Mater. 38, 266-272.

Kim S, Kim K S, Kim S S, Suganuma K, and Izuta G (2009a) Improving the reliability of Si die attachment with Zn-Sn-based high-temperature $\mathrm{Pb}$-free solder using a TiN diffusion barrier. J. Electron. Mater. $\mathbf{3 8}$, 2688-2675.

Lee J E, Kim K S, Suganuma K, Takenaka J, and Hagio K (2005) Interfacial properties of $\mathrm{Zn}-\mathrm{Sn}$ alloys as high temperature lead-free solder on Cu substrate. Mater. Trans. 46, 2413-2418.

Mahmudi R and Eslami E (2010) Inpression creep behavior of Zn-Sn hightemperature lead-free solders. J. Electron. Mater. 39, 2495-2502.

Moser Z, Dutkiewicz J, Gasior W, and Salawa J (1985) The Sn-Zn (tin-zinc) system. Bull. Alloy Phase Diagrams 6, 330-334.

Murray J L (1983) The Al-Zn (aluminum-zinc) system. Bull. Alloy Phase Diagrams 4, 55-73.

Okamoto H (2012) Sb-Sn (antimony-tin). J. Pahse Equilib. Diff. 33, 347.
Santos W L R, Brito C, Quaresma J M V, Spinelli J E, and Garcia A (2014) Platelike cell growth during directional solidification of a Zn-20wt\%Sn hightemperature lead-free solder alloy. Mater. Sci. Eng. B 182, 29-36.

Shi Y, Fang W, Xia Z, Lei Y, Guo F, and Li X (2010) Investigation of rare earthdoped BiAg high-temperature solders. J. Mater. Sci-Mater. El. 21, 875-881.

Shimizu T, Ishikawa H, Ohnuma I, and Ishida K (1999) Zn-Al-Mg-Ga alloys as $\mathrm{Pb}$-free solder for die-attaching use. J. Electron. Mater. 28, 11721175.

Song J M, Chuang H Y, and Wen X T (2007a) Thermal and tensile properties of Bi-Ag alloys. Metall. Mater. Trans. A 38, 1371-1375.

Song J M, Chuang H Y, and Wu Z M (2006) Interfacial reactions between Bi-Ag high-temperature solders and metallic substrates. J. Electron. Mater. 35, 1041-1049.

Song J M, Chuang H Y, and Wu Z M (2007b) Substrate dissolution and shear properties of the joints between Bi-Ag alloys and Cu substrate for high-temperature soldering applications. J. Electron. Mater. 36, 1516-1523.

Stadelmann P A (1987) EMS - a software package for electron diffraction analysis and HREM image simulation in materials science. Ultramicroscopy 21, 131-145.

Suganuma K (2004) Lead-Free Soldering in Electronics (Marcel Dekker, New York).

Suganuma K, Kim S J, and Kim K S (2009) High-temperature lead-free solders: properties and possibilities. JOM-US. 61, 64-71.

Takahashi T, Komatsu S, Nishikawa H, and Takemoto T (2010) Improvement of high-temperature performance of $\mathrm{Zn}$-Sn solder joint. $J$. Electron. Mater. 39, 1241-1247.

Takaku Y, Felicia L, Ohnuma I, Kainuma R, and Ishida K (2008) Interfacial reaction between $\mathrm{Cu}$ substrates and $\mathrm{Zn}$-Al base high-temperature $\mathrm{Pb}$ free solders. J. Electron. Mater. 37, 314-323.

Takaku Y, Makino K, Watanabe K, Ohnuma I, Kainuma R, Yamada Y, Yagi Y, Nakagawa I, Atsumi T, and Ishida K (2009) Interfacial reaction between $\mathrm{Zn}$-Al-based high-temperature solders and Ni substrate. J. Electron. Mater. 38, 54-60.

Vianco P T (2002) Solder technology for ultra high temperatures. Weld. J. 81, 51-54.

Wang C, Chen H, and Li P (2012) Interfacial reactions of high-temperature Zn-Sn solders with Ni substrate. Mater. Chem. Phys. 136, 325-333. 